\title{
An empirical study of the impact of knowledge acquisition, sharing and utilization on organizational performance of higher education institutions (HEIs), and the moderating role of organizational culture.
}

\author{
Armel Djangone, Dakota State University, Armel.Djangone@trojans.dsu.edu \\ Omar El-Gayar, Dakota State University,omar.el-gayar@dsu.edu
}

\begin{abstract}
Despite the amplified importance of knowledge management in organizations, there is a lack of studies exploring the interaction of knowledge management (KM) processes and organizational performance (OP), specifically in the perspective of higher education institutions (HEIs). This paper investigates the impacts of three KM processes, including knowledge acquisition, sharing, and utilization, on higher educational organizations' performance, in addition to the moderating effect of organizational culture in the context of higher education institutions (HEIs). In that regard, a model integrating higher educational performance with the three knowledge management processes and organizational culture is proposed and analyzed using SEM-PLS. This analysis showed that two of the three knowledge management processes, namely knowledge acquisition (KA) and utilization (KU), significantly affect organizational performance.
\end{abstract}

Keywords: knowledge management, organizational performance, organizational culture, higher education institutions.

\section{Introduction}

Across the world, businesses are now facing a common challenge in the wake of rapid changes in the corporate ecosystem (Obeidat et al., 2016). To survive in this economic environment, organizations need to improve their performance continually. Past studies revealed that the dynamic global business environment, which is highly dependent on managing knowledge effectively and efficiently, is at the heart of creating core competencies for an organization (Storey \& Barnett, 2000a). This has been supported by recent researchers (Muthuveloo et al., 2017) where they asserted that knowledge management is crucial for any organization seeking to prosper and enhance its organizational performance. Additionally, organizations are increasingly viewing Knowledge Management (KM) as their most valuable strategic asset. They are striving to find new ways to increase business performance by developing effective KM processes (Alaarj et al., 2016).

On developing such an effective KM practice, organizations must know how to manage their knowledge by expanding, disseminating, and exploiting it effectively. Additionally, organizations need to understand knowledge management (KM) success factors to be better equipped to implement KM practices effectively. KM success factors refer to all those factors, such as organizational culture (OC) behaviors that facilitate knowledge management (KM) processes or activities (Al-Hakim \& Hassan, 2016).

Since their inception, higher education institutions (HEIs) are considered by researchers as knowledgedriven organizations. They are primarily involved in learning and knowledge creation, developing, preserving, and dissemination through publications. Therefore, they have their place in society by 


\section{Issues in Information Systems}

Volume 22, Issue 4, pp. 278-289, 2021

generating new ideas (Ahmad et al., 2017; Fullwood \& Rowley, 2017). Similarly, higher education institutions (HEIs) can apply KM to support their missions by expanding knowledge-based practices in line with their institutional successes, particularly their performance.

Despite the vital role KM processes play in an organization, in general. Specifically, there are still issues related to the effects of KM processes on organizational performance (Shahzad et al. 2016) that require special attention.

This study attempts to complements prior work on knowledge management and performance of HEIs by examining the relationship between knowledge acquisition, utilization, sharing, and organizational performance of HEIs. Consequently, the study examines the moderating effect of organizational culture on these relationships. In the same vein, the research attempted to answer the following two research questions (RQ):

1. To what extent do knowledge acquisition, sharing, utilization impact the performance of HEIs?

2. How does organizational culture moderate the relationship between knowledge acquisition, sharing, utilization, and organizational performance of HEIs?

The remaining of the paper is organized as followed: first, an exploration of the literature necessary to understand the context of this study and a review of the existing body of knowledge are provided. Next, the research model and hypotheses are proposed and reviewed. Then, the research methodology is discussed. Finally, an analysis of the data is presented, followed by a discussion and conclusion.

\section{Literature review}

The section provides an overview of theories relevant to knowledge management processes and knowledge management in higher education. An overview of organizational performance and organizational culture is also presented. The section concluded by critically reviewing the current literature to identify the research gaps.

\section{Knowledge Management Processes}

There has been a lot of scholarly work conducted in the past on KM processes. Knowledge management processes are considered organized activities and give the researchers immense importance in organizational capabilities (Alaarj et al., 2016). This study focuses on knowledge acquisition, knowledge utilization, and knowledge sharing. Each one of these is discussed in more detail below.

According to Chiu et al. (2016.), knowledge acquisition results from employees' participation and interaction of people, resources, and technology. It also encompasses creating knowledge or innovation by using existing knowledge in an organization.

Knowledge sharing (KS) refers to exchanging knowledge between academics and researchers among peers within a university to enhance their knowledge base and that of their universities (Veer Ramjeawon \& Rowley, 2018). KS culture's subsistence helps higher educational organizations improve their research and teaching endeavors (Madbouly et al., 2020). Therefore, each HEI demands a culture and environment that facilitate KS through developing teamwork, networking, and collaboration (Madbouly et al., 2020).

According to Ramjeawon, P.V., and Rowley, J. (2018), Knowledge utilization refers to disseminating knowledge created by the academics and researchers within a university to external stakeholders or partners for its application and use and service to society. 


\section{Issues in Information Systems}

Volume 22, Issue 4, pp. 278-289, 2021

\section{Organization performance (OP)}

The growing challenges to the organization in either achieving or nurturing competitive advantage have made an organizational performance increase considerable attention to survive in such a highly competitive environment. As a result, organizational performance is regarded as an essential variable to measure organizational success. Mostly, there is an increasing emphasis on improving the operations of knowledgebased institutions. Measuring organizational performance is not a trivial task because it strongly affects the behavior of managers and employees.

\section{Organizational culture (OC)}

Organizational culture has emerged as an issue of vital interest within the business community for the last ten years (Tierney 1988). Accordingly, the number of studies on organizational culture is increasing. (Fleury (2009) pointed out that culture is a well-known topic in the academic plan, being discussed in dayto-day debates within organizations. Organizational culture is usually the element that drives the organization forward. It establishes an operational ecosystem in which every employee attempt to achieve the goal set by the organization (Narayana, 2017). Understanding culture is essential for the employees, the stakeholders, and the organization in general.

\section{Knowledge management in Higher education institutions (HEIs)}

The higher-education industry worldwide faces a dynamic and unstable environment due to tendencies such as changing demographics in the student" population, decreased public funding, and the greater importance of information and communication technology in the learning and teaching process. Further, higher education institutions (HEIs) have a long record in several facets of knowledge. According to (Ahmad et al., 2015), knowledge management promotes the services and processes of HEIs. These services and procedures include the research process, the curriculum development process, teaching and learning processes, student and alumni services, administrative services, and strategic planning. Knowledge management supports various functions in HEIs' administration. Examples include strategies for attracting prospective students, supplying information about HEIs resources and programs, and providing a rich information-filled environment for decision-making.

\section{Related work and the research gap}

A total of 219 employees from 26 universities in Pakistan responded to the survey study. Factor analysis and multiple regression techniques were used to test various hypotheses. The results revealed that KM processes have a significant positive impact on organization performance. In another study, Ahmad et al. (2015) investigated the effects of KM practices on OP. (Shahzad et al. (2016) found that the integration of knowledge strategy and KM processes leads to organizational creativity and performance. The results indicate that knowledge management practices significantly improve organizational performance (Ahmed et al., 2020). Alternatively, ((Mardani et al., 2018) asserted that KM processes influence OP through the use of other variables. These conflicting opinions reveal that KM's effects on firm performance are still ambiguous (Shahzad et al., 2016).

To the knowledge of the authors, no study investigated the role of culture. Further, very few of these studies established a link between the impact of KM on OP in the context of higher education institutions (Fullwood \& Rowley 2017.Pdf, n.d.). Accordingly, this paper aims further to examine the relationship between KM processes and OP, emphasizing the moderating effect of organizational culture. 


\section{Issues in Information Systems}

Volume 22, Issue 4, pp. 278-289, 2021

\section{Research Model and Hypothesis building}

\section{Conceptual model}

Figure 1 below shows the conceptual model of the study. The model depicts the relationship between KM processes: knowledge acquisition (KA), knowledge sharing (KS), and knowledge utilization (KU), and organization Performance (OP), and the moderating effect of organizational culture in the relationship between the three knowledge management processes and OP.

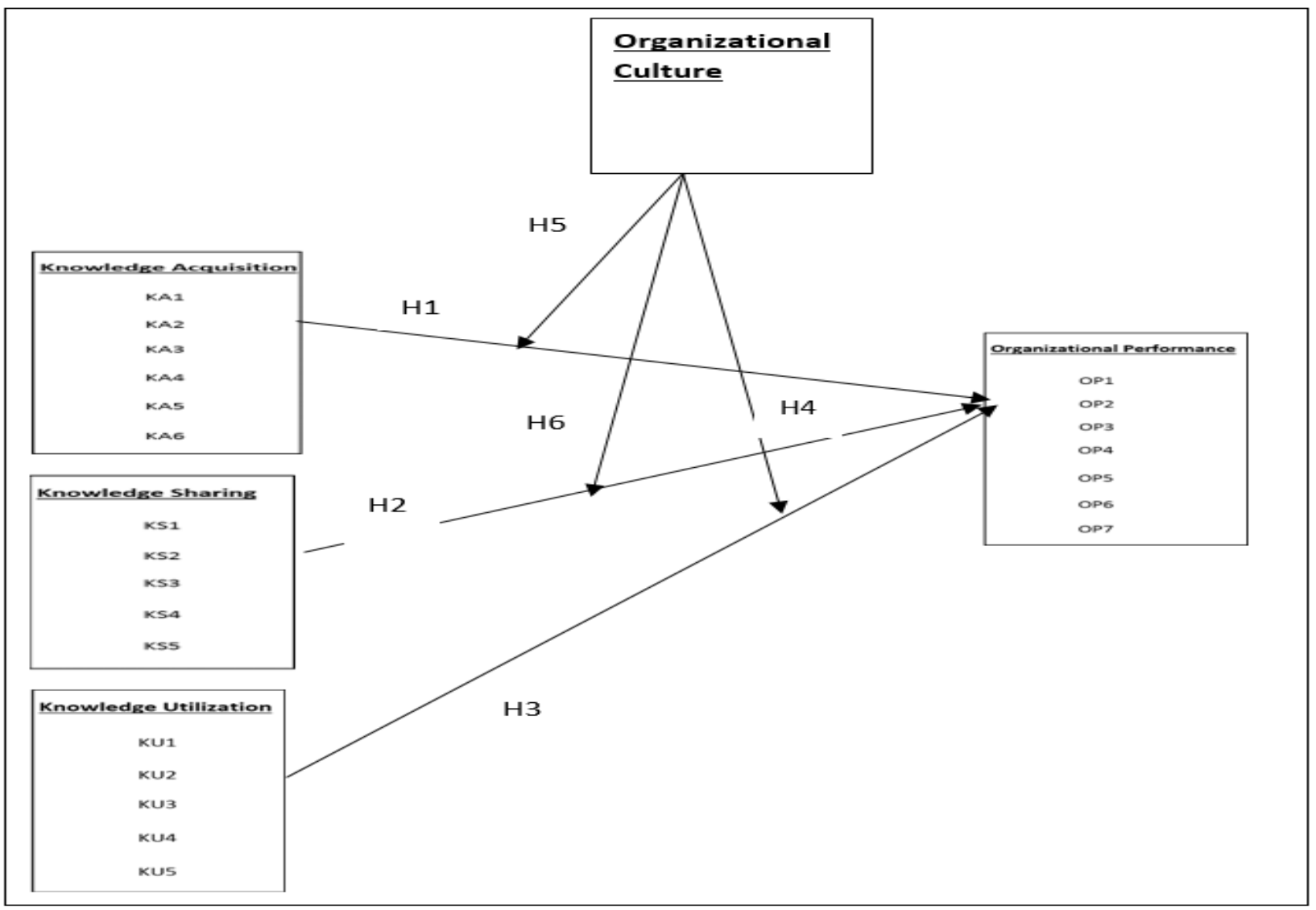

Figure 1. Conceptual model

\section{Hypothesis development}

\section{KM effectiveness and its impact on organization performance}

$\mathrm{KM}$ is equally essential in HEIs, such as research universities, due to its potential contribution to their performance (Masa'deh et al., 2017). For instance, knowledge acquisition, sharing, and utilization improve organizational collective learning and decision-making and enhance productivity and profitability (Chiu et al., 2016; Masa'deh et al., 2016). Many recent studies revealed a significant, positive, and direct association between KM processes and OP (Chiu et al., 2016; Shahzad et al., 2016) Additionally Ahmad et al. (2015) confirmed a positive and direct association between KM processes and universities' performance. Consequently, the following hypothesis can be deducted.

H1. Knowledge acquisition (KA) has a positive impact on the organization performance of HEIs. 


\section{Issues in Information Systems}

Volume 22, Issue 4, pp. 278-289, 2021

H2. Knowledge sharing (KS) has a positive impact on the organization performance of HEIs

H3. Knowledge utilization (KU) has a positive impact on the organization performance of HEIs

Organizational culture and its impact on the relationship between $K A, K S, K U$, and OP. knowledge management

The literature reveals that high organizational performance is associated with an organization having a strong culture with a practical and well-integrated set of behaviors and beliefs. Culture can support linkages between technology adoption and organizational growth, and it can be a critical success factor of KM. We hypothesize the following:

H4. Organizational Culture has a positive moderating positive impact on the relationship between Knowledge utilization and organization performance of HEIs.

H5. Organizational Culture has a positive moderating impact on the relationship between Knowledge acquisition and organization performance of HEIs.

H6. Organizational Culture has a positive moderating impact on the relationship between Knowledge sharing and organization performance of HEIs.

\section{Research Methodology}

\section{Survey instrument}

The survey instrument is comprised of two parts. The first part covers demographics-related questions such as gender, age, and other open-ended questions providing context and supporting future qualitative analysis of the results. The second part contained the research questions related to the different constructs: organizational performance, knowledge management-related constructs, and organizational culture-related constructs.

\section{Data Collection}

Data was collected using a survey disseminated to a sample of diverse individuals from an institution of higher education and who have experience in information systems. The institutions represent several private and public universities from the United States of America.

\section{Data Analysis}

Partial least squares structural equation modeling (PLS-SEM) was used to determine causal relationships. PLS-SEM, one of two categories of structural equation modeling (SEM), was selected due to its recognized capacity towards exploratory research in the social sciences and its fortitude towards estimating causative relationships between constructs (Hair et al., 2017). PLS-SEM is suitable for handling smaller sample sizes and makes no assumptions regarding data distribution (Wong, 2019). SmartPLS version 3.3.3 (Ringle et al. 2015) was used for PLS-SEM model estimation for its acceptance among the academic community and for its efficiency in assessment (Wong, 2019) 


\section{Results}

\section{Descriptive Statistics of Respondents}

Table 1 summarizes descriptive measures of collected demographics. We observe $48 \%$ of respondents were females, $22 \%$ were male. We also keep that $29 \%$ of the respondents were over 50 years, and $86 \%$ of the higher institutions were public, $8 \%$ were private, not-for-profit, and $5 \%$ were private for-profit institutions. A total of 70 responses were collected.

Table 1: Descriptive Statistics of Respondents

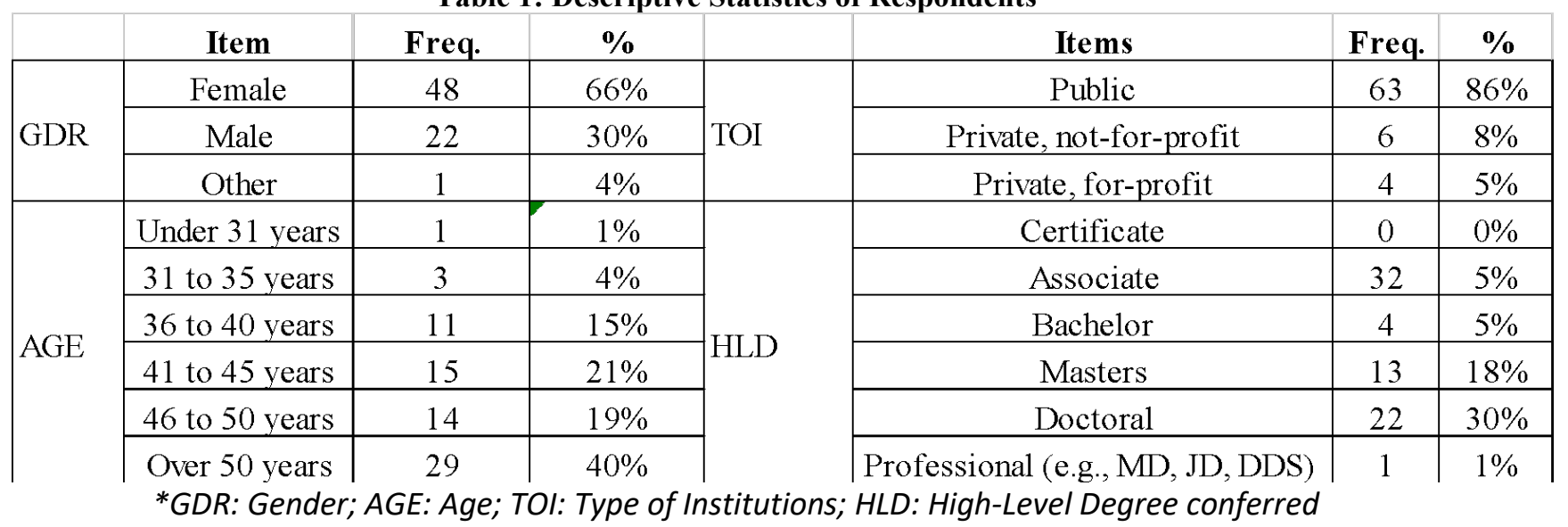

\section{Measurement Model Testing}

Table 2 summarizes the quality metrics for the measurement model, including tests for convergent validity, internal consistency reliability, and discriminant validity with a significance level (alpha) of 0.05 and biascorrected (BC) for interval analysis. All loadings exceed the recommended value of 0.70 , accounting for a minimum of $50 \%$ of the variance for related constructs (Gao et al., 2017). AVE levels for all latent variables were higher than the recommended minimum value of 0.50 (Hair et al. 2017), affirming convergent validity. Internal consistency was compared with accepted values of 0.60 and 0.70 for Cronbach's alpha and composite reliability (CR), respectively. All constructs passed, indicating no issues with internal consistency (Hair et al., 2017). Two criteria of Heterotriat-monotrait (HTMT) were reviewed to assess discriminant validity, including an HTMT ratio of correlations score below the cutoff of 0.85 (Hair et al. 2020) and an HTMT interval not containing one, considering a confidence level (CI) of 95\% (Hair et al. 2017; Wong 2019). All constructs passed both criteria, confirming discriminant validity. 


\section{Issues in Information Systems}

Volume 22, Issue 4, pp. 278-289, 2021

Table 2: Measurement Model Test Summary

\begin{tabular}{l|c|c|c|c|c|c|c}
\hline & \multicolumn{3}{c}{ Convergent Validity } & \multicolumn{2}{c}{ Internal Consistency Reliability } & \multicolumn{2}{|c}{ Discriminant Validity } \\
\cline { 2 - 8 } \multirow{2}{*}{$\begin{array}{c}\text { Latent } \\
\text { Variables }\end{array}$} & Loadings & IR (rho_A) & AVE & $\begin{array}{c}\text { Cronbach's } \\
\text { Alpha }\end{array}$ & $\begin{array}{c}\text { Composite } \\
\text { Reliability }\end{array}$ & \multicolumn{2}{|c}{ HTMT } \\
\cline { 2 - 8 } & $>0.70$ & $>0.50$ & $>0.50$ & $>0.60$ & $>0.70$ & $<085$ & Cl \\
\hline KA & Yes & 0.895 & 0.682 & 0.881 & 0.914 & Yes & Yes \\
\hline KS & Yes & 0.907 & 0.740 & 0.884 & 0.919 & Yes & Yes \\
\hline KU & Yes & 0.951 & 0.868 & 0.949 & 0.963 & Yes & Yes \\
\hline OP & Yes & 0.853 & 0.576 & 0.853 & 0.891 & Yes & Yes \\
\hline OC & Yes & 0.962 & 0.717 & 0.96 & 0.965 & Yes & Yes \\
\hline
\end{tabular}

\section{Structural Model Testing}

The structural model was estimated utilizing the PLS algorithm with complete bootstrapping using the biascorrected confidence interval method, two-tailed test, 5,000 subsamples, and mean replacement for missing values. Table 3 shows the results of the estimation of endogenous variables. The results indicate an explained variances of $55.3 \%$ for the OP with a p-value of 0.000 . Blindfolding (omission distance of 7 ) was the method used to calculate Stone-Geisser's Q2, which measures the predictive relevance of the model (Wong 2019). Overall, the results indicate a better than moderate predictive relevance for OP.

Table 3: Endogenous Variable Summary

\begin{tabular}{|c|c|c|c|c|c|c|c|}
\hline \multirow{2}{*}{$\begin{array}{c}\text { Endogenous } \\
\text { Latent } \\
\text { Variables }\end{array}$} & \multicolumn{3}{|c|}{ Coefficient of Determination (R2) } & \multicolumn{3}{|c|}{ R2 Adjusted } & \multirow[b]{2}{*}{$\begin{array}{c}\text { Predictive } \\
\text { Relevance 02 }\end{array}$} \\
\hline & Value & $\begin{array}{c}\text { Confidence } \\
\text { Interval (BC) }\end{array}$ & p-value & Value & $\begin{array}{c}\text { Confidence } \\
\text { Interval }(\mathrm{BC})\end{array}$ & p-value & \\
\hline $\mathrm{OP}$ & 0.553 & {$[0.405,0.658]$} & 0.000 & 0.505 & {$[0.452,0.685]$} & 0.000 & 0.281 \\
\hline
\end{tabular}

Table 4 shows the results regarding the exogenous variables' effects on endogenous variables. This includes moderating effects of OC. Considering VIF values of under 5.0, multicollinearity is not an issue for all hypothesized relationships (Hair et al. 2013) except for H3 with a VIF value of 5.357. Based on path coefficients and significance, the results support hypothesis $\mathrm{H} 1$ at an alpha of $0.01(* * *), \mathrm{H} 3$ at an alpha of 0.05 (**). However, $\mathrm{H} 2, \mathrm{H} 4, \mathrm{H} 5$, and $\mathrm{H} 6$ were well beyond acceptable significance levels, indicating failure to infer any effect in the relationships between latent constructs $(\mathrm{H} 2)$ and the moderating effect of culture (H4, H5, and H6). Effect size (f2) denotes the impact of exogenous variables on an endogenous variable, with $0.02,0.15$, and 0.35 being criteria for small, medium, or significant effects, respectively(Hair et al., 2013). Of the meaningful relationships identified, H3 had a somewhat medium impact. 


\section{Issues in Information Systems}

Volume 22, Issue 4, pp. 278-289, 2021

\begin{tabular}{|c|c|c|c|c|c|c|}
\hline Hypothesis & Relationship & $\begin{array}{c}\text { VIF } \\
<\mathbf{5 . 0}\end{array}$ & $\begin{array}{c}\text { Path } \\
\text { Coefficient }\end{array}$ & $\begin{array}{c}\text { Confidence } \\
\text { Interval } \\
\text { (BC) }\end{array}$ & p-value & $\begin{array}{c}\text { Effect Size } \\
\text { (f12) }\end{array}$ \\
\hline H1 & $\mathrm{KA}->\mathrm{OP}$ & 3.664 & 0.314 & {$[0.008,0.017\rceil$} & 0.02 & 0.06 \\
\hline $\mathrm{H} 2$ & $\mathrm{KS}->\mathrm{OP}$ & 4.759 & 0.121 & {$[-0.281,0.511]$} & 0.555 & 0.007 \\
\hline $\mathrm{H} 3$ & $\mathrm{KU}->\mathrm{OP}$ & 5.357 & 0.579 & $\lceil 0.258,1.059\rceil$ & 0.006 & 0.14 \\
\hline $\mathrm{H} 4$ & $\mathrm{KU}^{*} \mathrm{OC}->\mathrm{OP}$ & 3.49 & 0.066 & {$[-0.340,0.398]$} & 0.723 & 0.003 \\
\hline H5 & $\mathrm{KA}^{*} \mathrm{OC}->\mathrm{OP}$ & 3.947 & -0.186 & {$[-0.503,0.298]$} & 0.359 & 0.019 \\
\hline H6 & $\mathrm{KS}^{*} \mathrm{OC}->\mathrm{OP}$ & 0.048 & 0.031 & {$[-0.304,0.472]$} & 0.876 & 0.001 \\
\hline
\end{tabular}

\section{Moderator Analysis}

For moderator analysis, the path coefficient is reflective of the interaction term. The three graphs are shown in Figure 2 exhibit the slope analysis of the moderating effect of $\mathrm{OC}$ on these relationships when using the two-stage approach for creating the interaction terms.

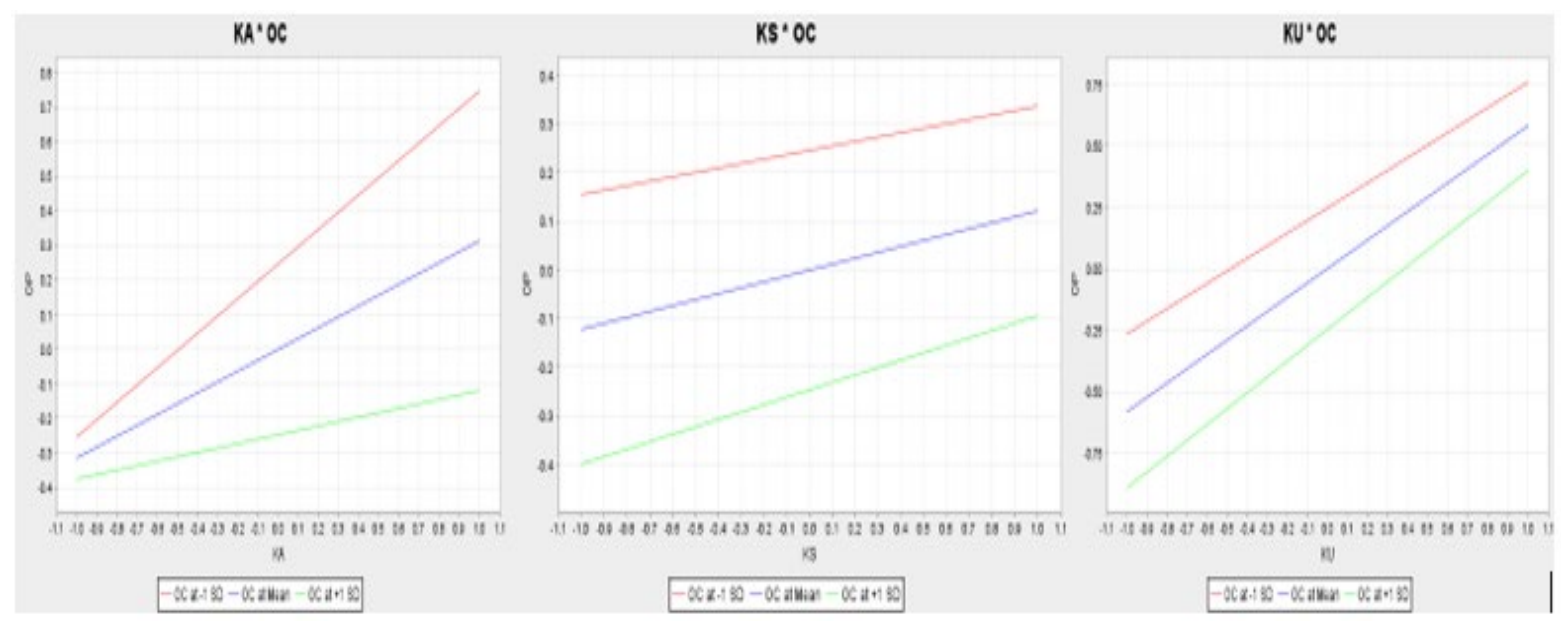

Figure 2: Moderator Slope Analysis

The $\mathrm{x}$-axis signifies the exogenous variable, and the y-axis represents the OP endogenous variable. The red line indicates the effect of OC at mean, the blue bar at -1 standard deviation (SD), and the green line at +1 SD. Regarding KA, we note a significant decrease in the influence of KA on OP with lower levels of OC (blue line). This is reflected in the interaction term of -0.186 and directly correlates with $\mathrm{H} 5$. We note a medium effect (0.019) of OC on the KA/OP relationship.

Regarding KS, we note no apparent interaction. It directly correlates with H6. Specific to moderator analysis, effect sizes (f2) of $0.005,0.01$, and 0.25 are the criteria for a small, medium, or significant effect, respectively (Hair et al., 2017; Hair et al., 2019). Consequently, we note a somewhat significant effect (0.019) of OC on the KA/OP relationship. Regarding KU, we observe a substantial decrease in the influence of $\mathrm{KU}$ on OP. This is reflected in the interaction term of 0.066 , and it directly correlates with $\mathrm{H} 4$. We note a minimal effect $(0.003)$ of OC on the KU/OP relationship. 


\section{Issues in Information Systems}

Volume 22, Issue 4, pp. 278-289, 2021

\section{Discussion}

This study aimed to investigate the impacts of knowledge acquisition, sharing, and utilization on organizational performance and explore the moderating effect of corporate culture in the context of higher education institutions (HEIs). The hypothesized relationships were tested using PLS-SEM. The overall result confirmed the positive relationship between components of knowledge management processes and organizational performance, most notably knowledge acquisition (H1) and knowledge utilization (H3) had a positive impact on the performance of HEIs. The results of this study are consistent with previous studies (Jyoti \& Rani, 2017; Hussinki et al., 2017, Ahmad et al. (2015)), mentioning that organizations that promote their employees generate, share, use and apply new knowledge perform better. This result indicates that knowledge acquisition and utilization matters for higher education institutes that always endeavor to be equipped with the latest and updated inside and transfer them to their students.

Hypothesis $\mathrm{H} 2$ examined the impacts of knowledge sharing on the performance of HEI. The results reveal that $\mathrm{H} 2$ is not supported. The findings suggest that knowledge-sharing activities do not have any effect on organizational performance. This study corroborates the findings of the Muqadas'study, whose study highlighted the challenges of knowledge sharing in the educational sector and identified the factors that facilitate knowledge sharing (KS), which would positively impact organizational performance. Previous studies suggest that KS can promote positive organizational outcomes, such as creativity; technological innovation, managerial effectiveness; organizational success, performance, learning, and improved problem solving (Chiu \& Chen, 2016, 2016; Muqadas et al., 2017).

H4, H5, H6 examined the moderating effect of organizational culture on the relationship between knowledge utilization, acquisition, and sharing, respectively, and educational organizations' performance. The findings reveal that H4, H5, H6 were not supported. In addition, the moderator slope analysis shows that organizational culture significantly decreases the positive impact of knowledge acquisition on the performance of HEIs. Similarly, corporate culture reduces the positive effect of knowledge utilization on the performance of HEIs.

\section{Conclusion}

This study was conducted to investigate the impacts of three knowledge management processes, including knowledge acquisition, sharing, and utilization, on educational organizations' performance, in addition to the moderating effect of organizational culture in the context of higher education institutions (HEIs). Using a quantitative survey method, the results demonstrate that knowledge acquisition and knowledge utilization positively impact the performance of higher education institutions in the USA. The results also indicate that organizational culture negatively moderates the relationship between knowledge acquisition and organizational performance. Educational institutions Administrators and Leaders can use these results to consult with investors about implementing KM projects. This study also contributes to practitioners, as it provides organizations with new insights and findings that HEIs administrators or managers from other industries can convert into their own companies.

This study has several limitations which may open doors for future studies. First, the study targeted faculty members only from the public and private universities. Further research may also include other employees of higher education institutions such as staff and administration. Second, the sample size of 70 respondents is relatively small. Third, the study was conducted on colleges and universities exclusively in the USA. A study with larger sample size and expanded to other developed countries may lead to a more generalized result. Last but not least, opportunities for more research exist to explore a moderator analysis based on respondent demographics such as position. 


\section{Issues in Information Systems}

Volume 22, Issue 4, pp. 278-289, 2021

\section{References}

Ahmad, N., Lodhi, M. S., Zaman, K., \& Naseem, I. (2015). Knowledge Management: A Gateway for Organizational Performance. Journal of the Knowledge Economy, 8(3), 859-876.

https://doi.org/10.1007/s13132-015-0282-3

Ahmed, T., Khan, M. S., Thitivesa, D., Siraphatthada, Y., \& Phumdara, T. (2020). Impact of employees engagement and knowledge sharing on organizational performance: Study of HR challenges in COVID19 pandemic. Human Systems Management, 39(4), 589-601. https://doi.org/10.3233/HSM-201052

Alaarj, S., Abidin-Mohamed, Z., \& Bustamam, U. S. B. A. (2016). Mediating Role of Trust on the Effects of Knowledge Management Capabilities on Organizational Performance. Procedia - Social and Behavioral Sciences, 235, 729-738. https://doi.org/10.1016/j.sbspro.2016.11.074

Al-Hakim, L. A., \& Hassan, S. (2016). CORE REQUIREMENTS OF KNOWLEDGE MANAGEMENT IMPLEMENTATION, INNOVATION, AND ORGANIZATIONAL PERFORMANCE. Journal of Business Economics and Management, 17(1), 109-124. https://doi.org/10.3846/16111699.2012.720597

Chiu, C.-N., \& Chen, H.-H. (2016). The study of knowledge management capability and organizational effectiveness in Taiwanese public utility: The mediator role of organizational commitment. SpringerPlus, 5(1), 1520. https://doi.org/10.1186/s40064-016-3173-6

Fleury, M. T. L. (2009). Organizational culture and the renewal of competences. BAR - Brazilian Administration Review, 6(1), 1-14. https://doi.org/10.1590/S1807-76922009000100002

Fullwood, R., \& Rowley, J. (2017). An investigation of factors affecting knowledge sharing amongst UK academics. Journal of Knowledge Management, 21(5), 1254-1271. https://doi.org/10.1108/JKM-07$\underline{2016-0274}$

Hair, J. F., Ringle, C. M., \& Sarstedt, M. (2013). Partial Least Squares Structural Equation Modeling: Rigorous Applications, Better Results, and Higher Acceptance. Long Range Planning, 46(1-2), 1-12. https://doi.org/10.1016/j.1rp.2013.01.001

Hair, J.F., Hult, G.T.M., Gingle, C.M., and Sarstedt, M. 2017. A Primer on Partial Least Squares Structural Equation Modeling (PLS-SEM), 2nd Edition. Thousand Oaks, CA: Sage Publications.

Hair, J. F., Risher, J. J., Sarstedt, M., \& Ringle, C. M. (2019). When to use and how to report the results of PLS-SEM. European Business Review, 31(1), 2-24. https://doi.org/10.1108/EBR-11-2018-0203

Hair, J.J.F., Howard, M.C., and Nitzl, C. (2020). "Assessing Measurement Model Quality in PLS-SEM Using Confirmatory Composite Analysis," Journal of Business Research (109), 03/01/March 2020, pp. 101110 .

Hussinki, H., Ritala, P., Vanhala, M., \& Kianto, A. (2017). Intellectual capital, knowledge management practices and firm performance. Journal of Intellectual Capital, 18(4), 904-922.

Jyoti, J., \& Rani, A. (2017). High performance work system and organisational performance: Role of knowledge management. Personnel Review, 46(8), 1770-1795. 


\section{Issues in Information Systems}

Volume 22, Issue 4, pp. 278-289, 2021

Madbouly, A., Gupta, V., Reyad, S., \& Soundarajan, G. (2020). The Impact of Knowledge Management on the HEIs' Innovation Performance: An analytical study of Omani HEIs. 5(0130), 20.

Mardani, A., Nikoosokhan, S., Moradi, M., \& Doustar, M. (2018). The Relationship Between Knowledge Management and Innovation Performance. The Journal of High Technology Management Research, 29(1), 12-26. https://doi.org/10.1016/j.hitech.2018.04.002

Masa'deh, R.E., Shannak, R., Maqableh, M. and Tarhini, A. (2017), "The impact of knowledge management on job performance in higher education: the case of the University of Jordan," Journal of Enterprise Information Management, Vol. 30 No. 2, pp. 244-262

Muqadas, F., Rehman, M., Aslam, U., \& Ur-Rahman, U.-. (2017). Exploring the challenges, trends, and issues for knowledge sharing: A study on employees in public sector universities. VINE Journal of Information and Knowledge Management Systems, 47(1), 2-15. https://doi.org/10.1108/VJIKMS-06$\underline{2016-0036}$

Muthuveloo, R., Shanmugam, N., \& Teoh, A. P. (2017). The impact of tacit knowledge management on organizational performance: Evidence from Malaysia. Asia Pacific Management Review, 22(4), 192 201. https://doi.org/10.1016/j.apmrv.2017.07.010

Narayana, A. (2017). A Critical Review of Organizational Culture on Employee Performance. American Journal of Engineering and Technology Management, 2(5), 72.

https://doi.org/10.11648/j.ajetm.20170205.13

Obeidat, B. Y., Al-Suradi, M. M., Masa'deh, R., \& Tarhini, A. (2016). The impact of knowledge management on innovation. Management Research Review, 39(10), 1214-1238. https://doi.org/10.1108/MRR-09-2015-0214

Ringle, C.M., Wende, S., and Becker, J.-M. 2015. "Smartpls 3." Boenningstedt: SmartPLS GmbH.

Veer Ramjeawon, P., \& Rowley, J. (2018). Knowledge management in higher education institutions in Mauritius. International Journal of Educational Management, 32(7), 1319-1332. https://doi.org/10.1108/IJEM-05-2017-0129

Shahzad, K., Bajwa, S. U., Siddiqi, A. F. I., Ahmid, F., \& Raza Sultani, A. (2016a). Integrating knowledge management (KM) strategies and processes to enhance organizational creativity and performance: An empirical investigation. Journal of Modelling in Management, 11(1), 154-179. https://doi.org/10.1108/JM2-07-2014-0061

Storey, J., \& Barnett, E. (2000a). Knowledge management initiatives: Learning from failure. Journal of Knowledge Management, 4(2), 145-156. https://doi.org/10.1108/13673270010372279

Tierney, W. G. (1988). Organizational Culture in Higher Education: Defining the Essentials. The Journal of Higher Education, 59(1), 2. https://doi.org/10.2307/1981868

Wong, K.K.-K. 2019. Mastering Partial Least Squares Structural Equation Modeling (PLS-SEM) with Smartpls in 38 Hours. Bloomington, IN: iUniverse. 